\title{
Taking the first step - what determines German laser source manufacturers' entry into innovation networks?
}

\author{
Muhamed Kudic ${ }^{1}$, Andreas Pyka² \& Jutta Günther ${ }^{3}$ \\ ${ }^{1}$ Department for Economic and Statistical Analyses, Stifterverband \\ Association for the Promotion of Sciences and Education in Germany \\ ${ }^{2}$ Chair for Economics of Innovation, University of Hohenheim \\ ${ }^{3}$ Chair for Economics of Innovation and Structural Change, University of Bremen
}

\begin{abstract}
Early access to technological knowledge embodied in an industry's innovation network can prove an important competitive advantage for firms. Surprisingly, not much is known about the determinants of their initial entry into such networks. We analyze the propensity of firms for entering the industry's innovation network and their timing in doing so. More precisely, we seek to shed some light on the factors affecting the length of the time-span between a firm's founding and its first cooperation event. We apply a unique longitudinal event history dataset based on the full population of German laser source manufacturers. Innovation network data stem from official databases providing detailed information on the organizations involved, the subject of joint research and development (R\&D) efforts, as well as the start and end times of all publicly funded R\&D projects between 1990 and 2010. Estimation results from an event history estimation model indicate that micro firms enter the network later than small or large firms. An in-depth analysis of the size effects for medium-sized firms provides some unexpected but highly interesting findings. The choice of cooperation type makes no significant difference to a firm's timing in entering the network. Finally, the analysis of geographical determinants shows that cluster membership can, but does not necessarily affect the timing of a firm's decision to cooperate.
\end{abstract}

Keywords: German laser industry; innovation networks; timing to cooperate; event history

Publication information: This article was published as Muhamed Kudic, Andreas Pyka, \& Jutta Guenther (2015) Taking The First Step-What Determines German Laser Source Manufacturers Entry Into Innovation Networks?, International Journal of Innovation Management, 19(05), 1550050, DOI: $\underline{10.1142 / \mathrm{S} 1363919615500504}$ 


\section{Introduction}

Since technologies are becoming more and more complex, the focus of innovation resides not only within the firm, but also outside, at the interface between firms, universities, research laboratories and so on. Many innovations require collective efforts by highly specialised organisations, involving different partners who act co-operatively (Chesbrough, 2003; Hagedoorn et al., 2000). It is now widely acknowledged that co-operative arrangements, despite the difficulties that might accompany co-operation, have a generally positive impact on a firm's innovation performance (Powel et al., 1996; Schwartz et al., 2012; Fritsch and Slavtchev, 2007; Pyka, 2002; Roxenhall, 2013).

The motives behind entering R\&D collaborations are manifold and range from cost savings and risk reduction (Hagedoorn, 1993, 2002; Sivadas and Dwyer, 2000), to knowledge access and interorganisational learning issues (Rothaermel, 2001; Grant and Baden-Fuller, 2004; Kale et al., 2000), to savings in time (Mowery et al., 1996). These and many related issues have become the focus of debate in innovation management (Moeller and Svahn, 2009, 2006; Tidd et al., 2005). Given the importance of innovation networks, it is all the more astonishing that the structural change of innovation networks remains more or less absent from the research agenda. Over the past years only a few groundbreaking studies have addressed the emergence (Gulati and Gargiulo, 1999; Hite and Hesterly, 2001) and evolution of networks (Powell et al., 2005; Koka et al., 2006). Most recently, researchers have begun to apply stochastic simulation techniques in order to shed some light on tie formation processes and the evolution of innovation networks (Van de Bunt and Groenewegen, 2007; Giuliani, 2010; Balland et al., 2012; Buchmann and Pyka, 2014).

Although previous research has provided us with important insights, we argue that one important part of the puzzle is missing. This is an understanding of the very nature and underlying logic of firms' network entry processes and hence the emergence and evolution of innovation networks at higher aggregation levels. There is still very little specific information available on the determinants that have an influence on a firm's first co-operative venture. To the best of our knowledge there are no previous studies that have explicitly addressed a firm's timing and propensity to enter the industry's innovation network. ${ }^{1}$

\footnotetext{
${ }^{1}$ For an overview, see Cantner and Graf (2011). In a similar vein, Jenssen and Nybakk (2013) discuss the influence of various determinants on the development of inter-organisational networks themselves.
} 
Consequently, at the very heart of this paper we analyse the determinants of a firm's propensity to co-operate for the first time and to enter the innovation network, and the timing of this decision. In essence, we scrutinise whether firms-specific, co-operation-specific or geographical factors affect the time lapse between a firm's founding and its network entry. An in-depth understanding of the network entry processes is important not only theoretically but also practically. More knowledge on this would be very valuable to innovation managers and policy makers in formulating co-operation strategies, overcoming friction and obstacles to cooperation and in conceptualising effective funding processes for science-driven industries.

In this paper we study a spatial sectoral innovation network based on a specific type of cooperative relationship: Formal, knowledge-related, publicly-funded R\&D projects that aim explicitly at increasing the innovativeness of the firms and organisations involved. We conduct the analysis on the German laser industry, an example of a highly knowledge intensive and science-driven industry (Grupp, 2000). Our data is unique in the sense that it covers firm characteristics and $R \& D$ co-operation activities for the entire population of German laser source manufacturers (LSMs) over a period of more than 20 years. This in itself constitutes a contribution to the literature on networks.

The structure of the paper is as follows: After this introduction, we provide our general theoretical considerations and development of hypotheses, largely influenced by an interdisciplinary and evolutionary economics perspective. We then continue with a description of the industry, data and research method. Finally, we present the results of our empirical study and draw conclusions.

\section{Theoretical Considerations}

Going beyond the R\&D co-operation motives already briefly discussed above, this section addresses the questions of how we can conceptualise innovation networks and of what determines network entry processes.

From a theoretical point of view, a network can be defined in the simplest terms as a welldefined set of nodes and the connections between them (Wasserman and Faust, 1994). For our purposes, this perspective falls short of the mark since we are particularly interested in the actors that are at risk of entering the network. Consequently, we have to differentiate between noncooperating firms, those organisations which are part of the industry and those that already participate in the industry's innovation network. We follow the suggestion of Guimera et al. (2005) and differentiate between two groups of potential network actors: "Incumbents" and 
"newcomers". These groups affect the dynamics of the network in a direct as well as an indirect way. Entries and exits of actors within the first group (i.e., active network actors) have direct consequences for the structural configuration of the network, whereas the same events affecting actors in the second group (i.e., potential network actors) have an indirect impact by enlarging or reducing the pool of co-operating partners who are potentially available. As we focus exclusively on network entry processes, in the following argument we consider only two of the several types of constellations that are theoretically possible, i.e., co-operation between two or more newcomers and co-operation between newcomers and incumbents.

This focus is consistent with the conceptualisation of innovation systems in economics (Lundvall, 1992). It has been argued that innovation is the outcome of interactions between heterogeneous economic actors (Pyka, 2002, 2007). According to Carlsson et al. (2002: 233), an innovation system is specified along several dimensions: A spatial or regional dimension ${ }^{2}$, a sectoral dimension ${ }^{3}$, or a technological dimension ${ }^{4}$. A spatial-sectoral innovation system can be seen as a broader and more general concept that entails geographically confined industry innovation networks (Kudic, 2015). The very purpose of such an innovation network is to exchange already existing information, knowledge and expertise with co-operating organisations in order to generate new knowledge together, which can be embodied in new products, services or processes (Cantner and Graf, 2011: 373). Both network incumbents and potential network entrants (newcomers) are part of the system. Firms within the system have a strong incentive to cooperate and enter the industry's innovation network as it provides access to technological knowledge of the industry.

Previous studies have discussed and analysed a broad range of mechanisms that were assumed to affect tie formation processes in networks. The preferential attachment concept provides a tie formation mechanism that is one of the most frequently discussed in network studies. The underlying logic is quite simple: Highly connected nodes are more likely than sparsely connected nodes to connect to new nodes (Barabasi and Albert, 1999; Albert and Barabasi, 2002). Several other mechanisms and aspects of logic underlying network formation processes have been discussed in the literature. These include "homophily", according to which actors

\footnotetext{
${ }^{2}$ The regional innovation system approach (RIS) is strongly influenced by the idea that innovation is the outcome of spatially or territorially determined learning processes between the actors in the system (Cooke, 2001).

${ }^{3}$ The sectoral innovation system approach (SIS) emphasises the cognitive dimension by arguing that interactive learning processes and subsequent innovation outcomes are fostered by the technological and contextual relatedness of the actors in the system (Malerba, 2002).

${ }^{4}$ The technological innovation system approach (TIS) focuses on generic technologies with general applications to many industries (Carlsson et al., 2002).
} 
with similarities are more likely to connect to one another (McPherson et al., 2001), "heterophily", in which heterogeneous actors attract one another (Amburgey et al., 2009), "herding behaviour", where economic actors follow the crowd (Kirman, 1993), and "transitive closure", according to which two nodes, both connected to a third partner, attract one another (Snijders et al., 2010; Giuliani, 2010; Ter Wal and Boschma, 2011; Buchmann and Pyka, 2014). Empirical evidence for a science-driven industry has been provided by Powell and his colleagues (2005). They analysed mechanisms such as "preferential attachment", "following the trend" and "multiconnectivity" in order to explain tie formation patterns in the US biotechnology industry's innovation network.

However, what is lacking in this discussion is an explicit consideration of timing issues. We argue that newcomer firms - which are part of the spatial-sectoral innovation system but not yet of the innovation network - that are able to enter the industry's innovation network earlier than their competitors gain a strategic advantage. Previous research indicates (Hagedoorn, 2006; Kudic, 2015) that at least three types of influential factors are likely to affect the timespan between the founding of a firm (i.e., entry to the innovation system) and its network entry (i.e., first $R \& D$ cooperation event with an incumbent or anther newcomer firm): (i) firm-specific factors, (ii) co-operation-specific factors and (iii) environmental factors.

To start with, we take a closer look at firm-specific determinants. The resource-based view of the firm (Wernerfelt, 1984; Barney, 1991; Peteraf, 1993) suggests that a firm's ability to achieve and maintain a profitable and competitive market position depends to a large extent on its ability to exploit both internal resources (Barney, 1991) and external resources (Gulati, 2007). It has been argued that small firms face considerable disadvantages when compared to larger firms, in the form of limited reputational, human capital and financial resources (Lu and Beamish, 2006). Small firms can overcome their resource constraints and counteract their comparatively high risk of failure — also known as "liability of smallness" (Barron et al., 1994) — by forming alliances with external partners (Baum et al., 2000). For instance, the innovation network study conducted by Jenssen and Nybakk (2009) shows that market participation of small knowledge intensive firms in product development has a positive impact on product, process and market innovation. Proponents of the knowledge-based view have argued that alliances allow firms to gain access to external knowledge stocks (Grant and Baden-Fuller, 2004) and to learn from cooperation partners (Hamel, 1991) in order to gain competitive advantages (Dierickx and Cool, 1989; Coff, 2003) and to survive the increasing pressure of global competition. 
However, given the necessity to co-operate and the willingness of these firms to do so, there are several factors that are likely to hamper their ability to co-operate and delay network entry. First, in the pre-cooperation phase it can be rather difficult to assess a potential partner's intentions (Dacin et al., 1997: 7). This raises the level of uncertainty, especially in international alliances (ibid.). Second, potential network entrants have to make considerable efforts, spending both time and limited resources on identifying potential co-operation partners (Dacin et al., 1997: 4). From a new institutional economics perspective (Ackerlof, 1970; Spence, 1976) we argue that a firm faces significant screening costs in overcoming information asymmetries and lowering the adverse selection risk. These search costs are likely, however, to impose a disproportionate burden on small firms because of their comparatively low resource endowment in the pre-cooperation phase. Once potential partners have been identified, other obstacles are likely to delay network entry. Most notable, small firms lack alliance management capabilities (Schilke and Goerzen, 2010) and standardised co-operation interfaces (Goerzen, 2005). Thus, we formulate our first hypothesis:

H1: Small firms take longer than large firms to enter an innovation network for the first time.

As far as co-operation-specific determinants are concerned, the question is how the type of cooperation influences the time it takes a firm to initiate its first cooperation event. An important difference between EU and national policies is that EU-framework projects explicitly aim to encourage scientific and technological co-operation between member states, whereas national funding initiatives address predominantly domestic applicants. There are some clear benefits associated with international R\&D project environments. According to Gunasekaran (1997: 639), these include access to new and different technologies, enhanced scope of potentially accessible technological knowledge stocks, better access to qualified employees and a broad range of training opportunities for technical personnel. Nonetheless, there are also some difficulties associated with international R\&D co-operation projects. The pre-formation phase is characterised by higher costs in identifying potential partners. In the post-formation phase, international alliances require greater efforts in co-ordination in order to support interactions (Lavie and Miller, 2008: 625). Project governance costs tend to be higher owing to higher levels of uncertainty (ibid.). In addition, it is commonly recognised that cross-national cultural differences (Hofstede, 2001) may affect interaction between firms and organisations in multiple ways. Firms entering cross-national co-operation projects face the challenge of adjusting both to a foreign country and to an alien corporate culture (Barkema et al., 1996: 154; Lavie and Miller, 2008: 626). Differences in national cultures are reflected in decision makers' differing 
managerial approaches and have the potential to significantly affect strategic decisions in both pre- and post-alliance formation phases (Dacin et al., 1997: 6). As a consequence, it has been argued that cross-national cultural differences are likely to affect a firm's attitude towards cooperation and thus its predisposition to enter international R\&D consortia (Nakamura et al., 1997: 155). These considerations underpin our second hypothesis:

H2: A firm will enter a national innovation network sooner than an international network (mode of entry).

Finally, we take a closer look at the contextual dimension. Based upon a proximity framework originally proposed by Boschma (2005), Boschma and Frenken (2010) argue that network change is likely to be affected by relational proximity and other dimensions of proximity such as cognitive, organisational, institutional or geographical proximity. In this paper, we focus on the relationship between geographical proximity and a firm's co-operation timing. More precisely, we distinguish between inside-cluster and outside-cluster firms and analyse the extent to which cluster membership affects the co-operation timing. It is important to note that cluster membership does not require or imply network membership. Firms can be located in a densely crowded region (agglomeration) without having formal co-operative partnerships with other firms or organisations in their immediate geographical neighbourhood.

We assume a positive relationship between a firm's location in an industrial agglomeration and its first co-operation activities. Feldman (1999) and Audretsch and Feldman (1996) argue that a local environment generates positive externalities in terms of knowledge spillovers. Further, social interactions between employees and decision makers within a regional agglomeration are an important information source. As a result, firms located in densely crowded industrial regions become aware of local co-operation opportunities sooner than others. It is therefore plausible that regional environments can speed up a firm's successful search for potential partners and shorten the time needed to enter the network. At the same time we should keep in mind that geographical proximity may also be accompanied by negative effects. Boschma (2005: 70) argues that highly specialised regions can become too inward looking and sensibilises for problems of spatial lock-in effects because of their lack of openness to the outside world. In line with Feldman (1999); Audretsch and Feldman (1996) and others we formulate our last hypothesis: 
H3: The time taken to first enter an innovation network is shorter in the case of firms located in densely crowded regions (agglomeration areas) than for those firms located in remote geographical regions.

\section{Industry, Data and Methods}

\section{Introducing the German laser industry}

The invention of the first laser device occurred in the late 1950s. The acronym laser stands for "Light Amplification by Stimulated Emission of Radiation" and was originally coined by Gordon R. Gould (1959) in his seminal article presented at the "Ann Arbor Conference on Optical Pumping". Just one year later Maiman (1960) put the first stable laser device into operation.

Over the past half-century noumerous groundbreaking technological advances were made in the field of modern laser research (cf. Hecht, 2010). Today, laser applications can be found in nearly every sphere of life, with output power ranging from $1-5 \mathrm{~mW}$ lasers for DVD-ROM drives or laser pointers to $1-5 \mathrm{~kW}$ lasers commonly used for industrial laser cutting, to petawattclass lasers $\left(10^{15} \mathrm{Watt}\right)$ used for experiments in plasma and atomic physics. In 2006 , the revenue from German laser sources and optical component producers reached approximately EUR 8.0 billion and about 45,000 people were employed in the industry (Giesekus, 2007: 11).

There are a number of salient arguments that advocate the use in our study of data from the German laser industry. Firstly, laser technology requires knowledge from various academic disciplines, such as physics, optics and electrical engineering (Fritsch and Medrano, 2015). It can clearly be characterised as a science-driven industry (Grupp, 2000) in which a firm's ability to innovate is a key factor in its performance and success. The interdisciplinary, knowledge intensive and science-based character of the industry is reflected in the high level of cooperative activities of German LSMs among themselves and with laser-related public organisations (PROs) (Kudic et al., 2011). Secondly, the economic potential of the industry has since become well recognised by national and supranational political authorities. Over the past few decades, Germany has developed into a world market leader in many fields of laser technology. Mayer (2004) reports that $40 \%$ of all laser beam sources purchased worldwide in 2003 were produced by German LSMs. Last but not least, the majority of contemporary empirical studies on the evolution of networks are based upon data from the biotech industry. Findings, however, can differ significantly due to inter-industry differences in terms of the industry's technological maturity; firm size distribution and industry life cycle stages (cf. 
Buchmann et al., 2013). Thus, an in-depth analysis of causes and consequences of micro-level network change processes based on data from other science-driven industries is clearly under represented but urgently needed.

\section{Data and methods}

Industrial sector classifications, such as the NACE, SIC or the German WZ classification, group firms into coarse-meshed categories based on historically rooted industry development patterns. This implies that LSMs cannot be clearly separated on the basis of these industry classification schemes. As a consequence, we employ industry data ${ }^{5}$ from a unique dataset containing detailed information on firm entries and exits for the entire population of German LSMs ${ }^{6}$ between 1969 and 2005 (Buenstorf, 2007). This initial industry dataset has been modified in several ways. Additional data sources were employed to gather supplementary information on firm entries and exits after 2005. In the first instance, we were given access to updated German laser industry data, provided by members of the LASSSIE project consortium ${ }^{7}$. In addition we used annually published laser industry business directories (i.e., "Europäischer Laser Markt”) provided by the B-Quadrat Publishing Company, data from Germany's official company register (i.e., "Bundesanzeiger”), industry data from the MARKUS database ${ }^{8}$, provided by Bureau van Dijk Publishing, and industry data from the Creditreform archival database, provided by the Creditreform Company. For the purpose of this study, we choose the firm and business-unit level because information on both $\mathrm{R} \& \mathrm{D}$ co-operation projects is commonly reported at the aggregation level. Based on these data sources, the complete life histories for all firms in the sample were reconstructed. Corporate level entities were decomposed and broken down into the business functions or market segments they served. Firm exits owing to insolvencies, mergers or acquisitions, and several modes of population entries were treated separately. Moreover, we included predecessors of currently existing firms and accounted for all changes in firm names and legal status to ensure the full traceability of a firm's origins and

\footnotetext{
${ }^{5}$ This dataset was originally compiled by Guido Buenstorf, Max-Planck Institute for Economics in Jena.

${ }^{6}$ Corporations were considered to be LSMs based on their actual business activities as reported in laser industry business registers and frequently published laser exhibition catalogue.

${ }^{7}$ The LASSSIE project is an interdisciplinary research project funded by the Volkswagen Foundation. The acronym LASSSIE stands for "Lasers: A Spatial-Sectoral System of Innovation and its Evolution". Again, special thanks go to Guido Buenstorf.

${ }^{8}$ The database contains information on 1.4 million officially registered companies in Germany, Austria and Luxembourg.
} 
development path. This process gave us an industry dataset encompassing 233 German LSMs over the entire observation period between 1990 and 2010.

Organisational level data was taken from the same raw data sources that were used at the industry level. Moreover, we used annually compiled count data from different types of laser related organisations - LSMs, laser-related PROs and laser system providers (LSPs) — again supplied by the LASSSIE project consortium. Data was available at the planning region level. This allowed us to identify planning regions with an above-average number of LSMs, PROs and LSPs and to group these planning regions into clusters.

Co-operation data used for this study came from two electronically available archive data sources: (i) The Foerderkatalog database ${ }^{9}$ provided by the German Federal Ministry of Education and Research (BMBF) and (ii) the CORDIS databases ${ }^{10}$ provided by the European community research and development information service (CORDIS).

In the first instance, we exploited the Foerderkatalog database to gather information on nationally funded $\mathrm{R} \& \mathrm{D}$ co-operation projects. This raw data source encompasses information on a total of more than 110,000 completed or ongoing subsidised research projects and provides detailed information on the starting point, duration, funding, project description and some additional information on the project partners involved. In total, we were able to identify 416 R\&D cooperation projects with up to 33 project partners from various industry sectors, nonprofit research organisations and universities.

Next, we exploited the CORDIS database to gain information on supranational funded R\&D co-operation projects. The CORDIS database encompasses all seven EU Framework Programs and covers a time span from 1983-2010. We were provided by the CORDIS support team, a database extract which includes a complete collection of $R \& D$ projects for all German companies which were funded by the European Commission. In total, this database extract consisted of a project dataset with over 31,000 project files and an organisation dataset with over 57,100 German organisations and roughly 194,000 international project partners.

Each project data file is identified by a project ID and a record ID and provides information on project content, prime and secondary contractors, starting and ending date of the project, total costs and total funding, the framework program and some further information. Data files in the organisation dataset are identified by an organisation ID and a project ID and provide detailed

\footnotetext{
${ }^{9} \mathrm{http}: / /$ foerderportal.bund.de/foekat, accessed: April 2011.

${ }^{10} \mathrm{http} / / /$ cordis.europa.eu/search, accessed: April 2011.
} 
information on an organisation's address, ZIP code, country code, project status and the contact information of the project co-ordinators. The project ID allowed us to link these two datasets in order to identify a complete list of R\&D projects for the entire sample of 233 LSMs. Based on this raw data, we identified $154 \mathrm{R} \& \mathrm{D}$ projects with up to 53 project partners for the entire observation period. We are not the first to use these archive data sources to construct knowledge-related innovation networks (cf. Broeckel and Graf, 2011; Fornahl et al., 2011; Scherngell and Barber, 2009: 2011; Cassi et al., 2008). There are sound arguments for the use of these archive data sources in analysing the evolution of innovation networks. Organisations that participate in $R \& D$ co-operation projects subsidised by the German federal state have to agree upon a number of regulations that facilitate mutual knowledge exchange and provide incentives for innovation (Broeckel and Graf, 2011: 6). In a similar vein, the EU has funded thousands of collaborative $R \& D$ projects in order to support transnational co-operation activities, increase mobility, strengthen the scientific and technological bases of industries and foster international competitiveness (Scherngell and Barber, 2009: 534). Both data sources provide exact information on the timing of tie formation as well as tie termination processes.

The single-episode event history dataset for the German laser industry is designed as follows: The time axis is defined on the basis of century months. All firm foundation dates as well as all start and end dates of co-operation events are expressed in century months. The unit of analysis is the firm. In cases where the number of censored observation units is small it is acceptable to simply exclude them (Allison, 1984: 11). Thus, firms founded before 1990 were excluded from the dataset to avoid left truncation and left censoring problems (Blossfeld and Rohwer, 2002: 39-41). Starting with the full population of 233 LSMs in our sample, we identified 39 firms that were founded before 1990. Thus, a total of 194 firms were potentially at risk of conducting the first co-operation event. From this population we ended up with a total of 112 firms with at least one or more co-operation events during the observation period. The event of interest is the first co-operation for all LSMs which are at risk in the time period between 1990-2010. The dataset allows us to analyse the transition from the origin state ("non-cooperation") to the destination state ("first co-operation"). These two states allow us to define the risk set. At the same time the initial co-operation event marks the firm's entry into the network. Repeated events were not considered. Firms were considered to have two basic ways of entering the German laser industry innovation network. The first co-operation event could be participating either in a Foerderkatalog project or in a CORDIS project. These cooperation types were coded separately. All event occurrence dates and durations were recorded in century months. Variables were grouped in the following categories: organisational, relational and contextual. 
Table 1 provides an overview of the variables used in this study. An organisational variable was included in the dataset to account for differences in firm size. Size categories were defined by using information on the number of employees in a given year. This categorisation is drawn upon the definition proposed by the European Commission (2005). Missing data for the number of employees were extrapolated based on employee data for the same firms but other observation windows. A simple relational variable was included in the dataset to account for the type of co-operation. Thus, nationally funded and supra-nationally funded R\&D cooperation projects were coded separately. Finally, we included a set of cluster variables in our dataset indicating whether a firm was located inside or outside an industrial agglomeration. We used planning regions to identify spatially concentrated agglomeration areas. Planning regions with three or more LSMs, PROs and LSPs in a given observation window were considered to be areas with an above average activity in the field of laser research and production. Based on this assumption we were able to identify four laser clusters. The variables and cluster definitions are outlined in more detail in Table 1.

Table 1. Variable specification

\begin{tabular}{|c|c|c|}
\hline Organisational level & Definition & Level \\
\hline $\begin{array}{l}\text { Size categories } \\
\text { Micro } \\
\text { Small-sized firm } \\
\text { Medium-sized firm } \\
\text { Large firm } \\
\end{array}$ & $\begin{array}{l}\text { 1-9 employees } \\
\text { 10-49 employees } \\
50-249 \text { employees } \\
\text { More than } 250 \text { employees } \\
\end{array}$ & $\begin{array}{l}\text { firmsize_cat_ev1 } \\
\text { firmsize_cat_ev2 } \\
\text { firmsize_cat_ev3 } \\
\text { firmsize_cat_ev4 }\end{array}$ \\
\hline Relational level & Definition & Label \\
\hline 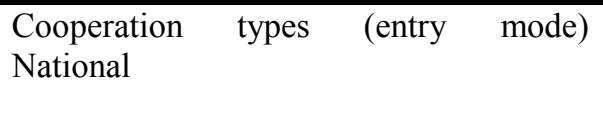 & $\begin{array}{l}\text { Nationally funded R\&D cooperation } \\
\text { projects ("Förderkatalog data") }\end{array}$ & Coop_type_fk \\
\hline International & $\begin{array}{l}\text { Supra-nationally funded R\&D } \\
\text { cooperation projects ("CORDIS data") }\end{array}$ & Coop_type_c \\
\hline Contextual level & Definition & Label \\
\hline $\begin{array}{l}\text { Cluster involvement } \\
\text { Baden-Wuttemberg Cluster } \\
\text { Bavaria Cluster } \\
\text { Thuringia Cluster } \\
\text { Berlin Cluster } \\
\end{array}$ & $\begin{array}{l}\text { Planning regions: } 72,73,74,76,77 \\
\text { Planning regions: } 86,90,93 \\
\text { Planning regions: } 54,56 \\
\text { Planning region: } 30\end{array}$ & $\begin{array}{l}\text { Clu_BW } \\
\text { Clu_Bav } \\
\text { Clu_Thu } \\
\text { Clu_B }\end{array}$ \\
\hline
\end{tabular}

\section{Empirical Model Specification and Results}

\section{Empirical estimation approach}

Non-parametric event history methods were used to test our hypotheses. For the purpose of this study, we applied the product-limit estimator, also known as the Kaplan-Meier method (Kaplan and Meier, 1958). This fairly simple but powerful estimation method has several advantages. It 
is straightforward to use, requires only weak assumptions and allows non-repeated events in single-episode event history data to be analysed (Cleves et al., 2008: 93). The method estimates the survivor function based on longitudinal event data for all firms under risk (ibid.). In general, the survivor function represents the probability of surviving past time $t$, or to put it another way, the probability of failing after time $\mathrm{t}$ (ibid.). In this study we are interested in German LSMs' propensity to co-operate for the first time. The unit of analysis is the firm. The time axis is defined on the basis of century months. All firm foundation dates as well as all start and end dates of co-operation events are given in century months. The event of interest is the first cooperation for all LSMs which are at risk in the time period between 1990 and 2010. The dataset allows us to analyse the transition from the origin state ("no-cooperation") to the destination state ("first cooperation"). Repeated events were not taken into account. Thus, the survival function has to be interpreted as follows: The survival function estimates a firm's probability of having the first co-operation event after a certain time $t$.

Non-parametric estimation methods allow the comparison of survivor functions. The overall population can be divided into two or more subgroups by using an indicator variable to analyse whether the probability of failing after time $t$ differs significantly among these subgroups. The indicator variable defines the membership in a particular subgroup (Blossfeld et al., 2007: 76). We apply this approach to analyse the extent to which organisational, relational and contextual determinants affect the co-operation behaviour over time. In this study, we make use of the most commonly applied test statistics, i.e., the Log-Rank test, Cox test, Wilcoxon-Breslow test and Tarone-Ware test. These tests are designed to compare globally defined, overall survival functions (Cleves et al., 2008: 123). Even though these tests provide relatively similar results in most cases, it is useful to calculate and compare alternative test statistics. One reason for this is that some tests (e.g., Wilcoxon-Breslow) emphasise differences in survivor functions at the onset of the observation period whereas other test statistics (e.g., Log-Rank) stress differences at the end of the observation period (Blossfeld, Golsch and Rohwer, 2007: 81). The Cox test is very similar to the Log-Rank test whereas the Tarone-Ware test, like the Wilcoxon-Breslow test, places more weight on earlier time periods (ibid.). Common to all these test statistics is the fact that they are $\chi^{2}$-distributed with $m-1$ degrees of freedom. The tests are based on the null hypothesis that the survivor functions do not significantly differ from one another (Blossfeld et al., 2007: 81). A significant test result indicates that the null hypothesis must be rejected (ibid.). 


\section{Empirical results}

A natural starting point is to look at the overall survivor function. Figure 1 indicates that after 50 century months (i.e., 4 years and 2 months) about $66 \%$ of all firms in our sample had entered the network, while about $34 \%$ of all firms were still not able to initiate their first co-operation event. Only 50 century months later (i.e., 8 years and 4 months) about $84 \%$ had realised their first co-operation event and, after 150 century months (i.e., 12 years and 6 months), 99.6\% of all firms had moved from the origin state to the destination state.

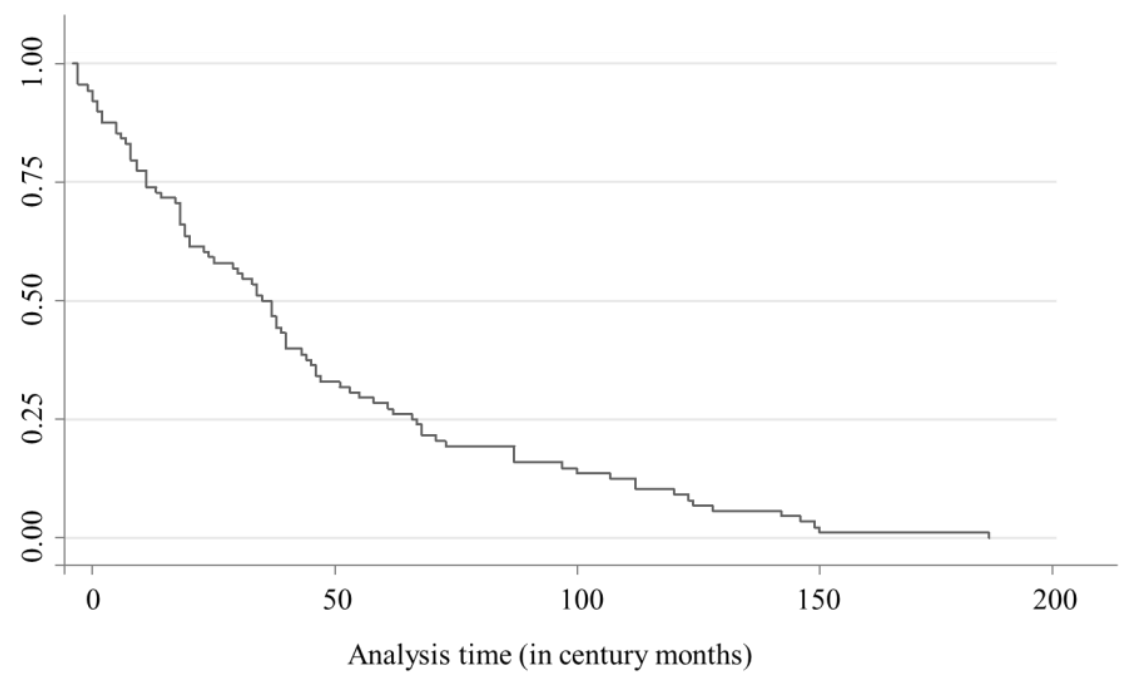

Fig. 1. Timing of cooperating and entering the network. (Source: Own calculations)

In order to test our hypotheses we have used several indicator variables to split the sample, compare survivor functions and analyse the extent to which the probability of entering the network is affected by organisational, relational or contextual factors.

We start the presentation and discussion of our findings by considering firm size. A comparison of survivor functions for micro, small, medium and large firms reveals some unexpected but interesting findings (Fig. 2). What we observe is that micro firms enter the network significantly later than small and large firms. The sequence in which micro, small and large firms enter the network remains unchanged and stable throughout the entire observation period. The test statistic displayed below of the survivor function plot indicates that the null hypothesis must be rejected, meaning that the survivor functions differ significantly from one another. These results seem to confirm, at least at first glance, our Hypothesis H1, according to which smaller firms have higher resource constraints and co-operate later than larger firms. However, the group of medium-sized firms complicates the story. At some point in time (e.g., after 50 months), 
medium-sized firms enter the network significantly later than large firms and micro- and smallsized firms. Simply put, we found partial support for Hypotheses H1. The findings for micro, small and large firms are in line with our expectations. Moreover, the results indicate clearly that, at least for medium-sized firms, there must be another underlying process affecting a firm's timing in entering the network.

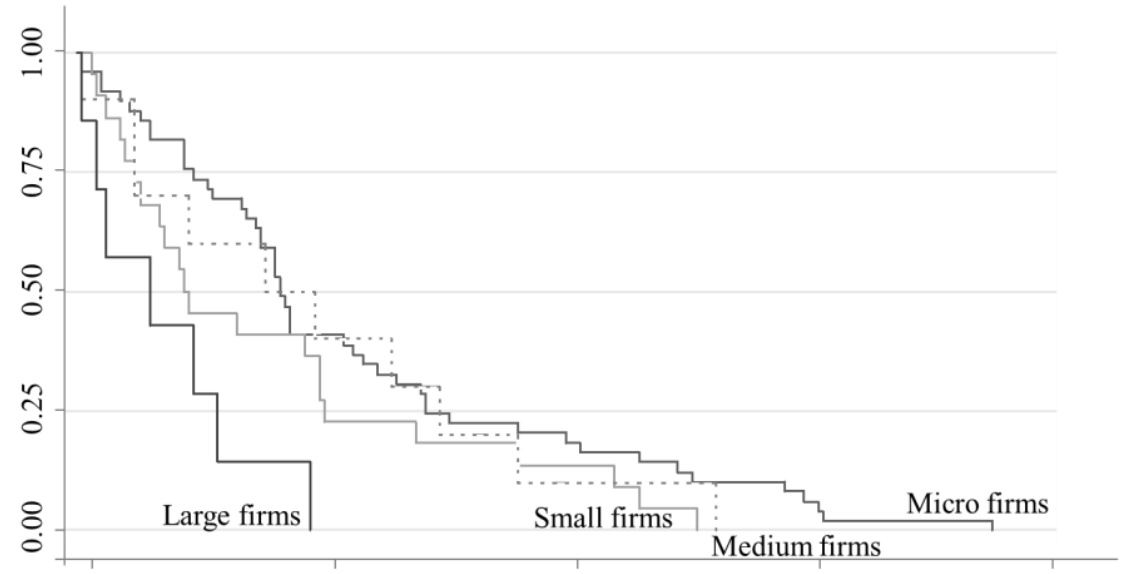

Analysis time (in century months)
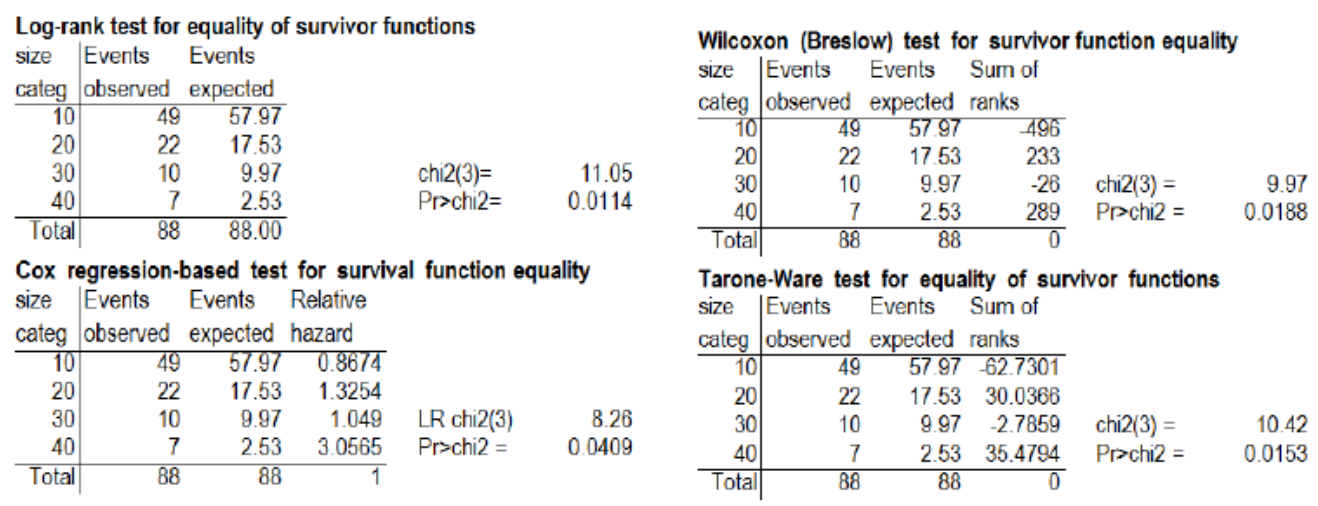

Fig. 2. Timing of cooperating and entering the network, by firm size. (Source: Own calculations)

Next, we look at the relational dimension. Our initial expectation was that the type of cooperation demonstrated by a firm when entering the network is likely to affect how long it will take for the first cooperation event to occur. Surprisingly, a comparison of nationally and supra-nationally funded R\&D projects shows no significant differences (Figure 3). All four test statistics indicate that the null hypothesis must be confirmed, meaning that there is no significant difference between the compared survivor functions. In other words, it makes no difference whether a firm favours nationally funded (i.e. Foerderkatalog projects) or supranationally funded (i.e. CORDIS projects) R\&D projects. The assumed difficulties of international R\&D cooperation projects, such as enhanced search or governance costs, seem to 
play a minor role only in the German laser industry. In a similar vein, the problem of "double layered acculturation" inherent in international cooperation projects (Barkema et al., 1996, 154) appears to play no significant role in this context. As a consequence we have to reject our Hypotheses H2.

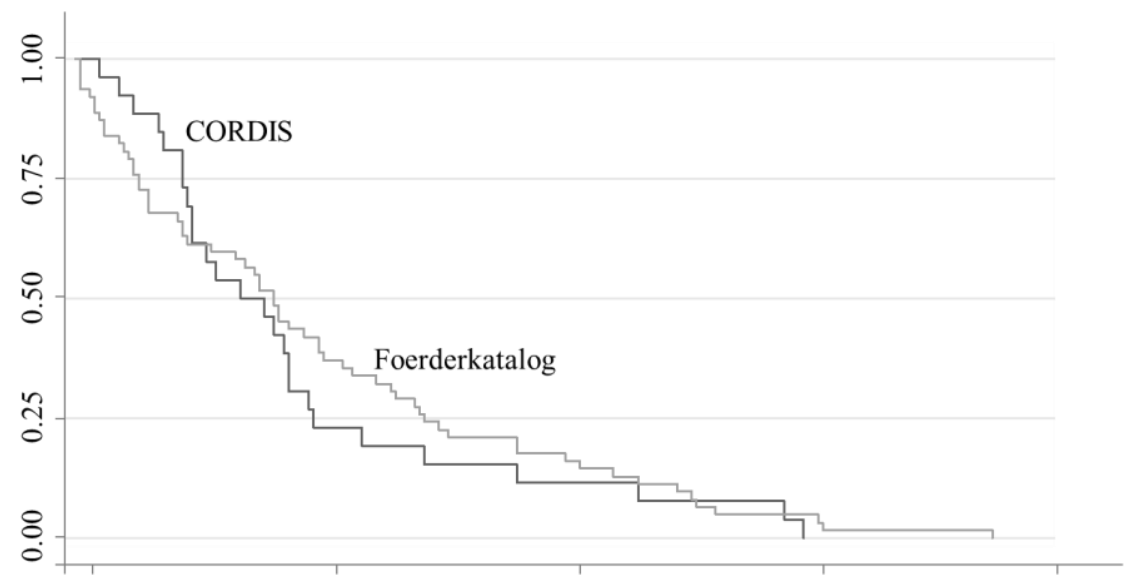

Analysis time (in century months)

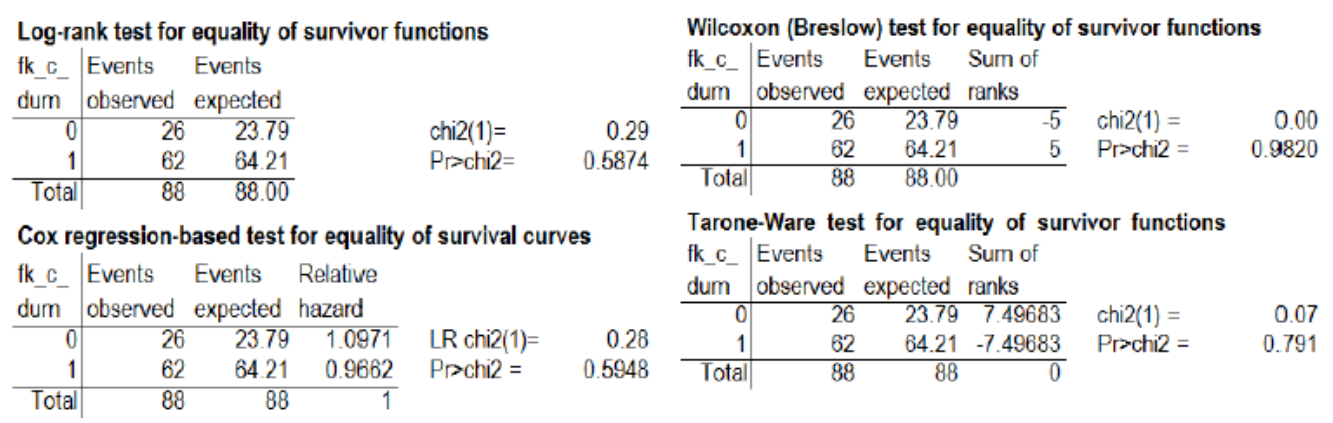

Fig. 3. Timing of co-operating and entering the network, by co-operation type. (Source: Own calculations)

Finally, we address only one of several other contextual determinants by taking a closer look at the geographical proximity dimension. In an effort to analyze the extent to which cluster membership affects a firm's timing in entering the network, we identified several planning regions with an above-average number of LSMs, PROs and LSPs and grouped them into four clusters: cluster_Thu, cluster_Bav, cluster_B and cluster_BW. Figure (4) illustrates our empirical results. Perhaps the most interesting finding is that cluster membership can have quite different effects on firms' timing in entering the network. Results show that firms located in the Thuringia Cluster (clu_Thu) cooperate significantly earlier than firms located elsewhere. This finding confirms both our expectations and our Hypothesis H3. Surprisingly, we also found empirical evidence for the existence of two other theoretically possible outcomes, that is, 
negative relatedness between cluster membership and network entry time and no relatedness between cluster membership and R\&D cooperation propensity and timing.

Our results show that firms located in the Bavarian Cluster (clu_Bav) enter the industry's innovation network significantly later than firms located elsewhere. In both cases, test statistics indicate that the compared survivor functions for inside-cluster and outside-cluster firms differ significantly. However, this is only half the story. Our results for the Berlin Cluster (clu_B) and the Baden Wurttemberg Cluster (Clu_BW) reveal a very different picture. In both cases we found no empirical evidence for significantly different survivor functions when comparing inside-cluster and outside-cluster firms. In summary, clusters can, but do not necessarily affect a firm's timing in cooperating and entering the network. Even though we found only partial support for Hypothesis H3, our empirical results provide some unexpected but very interesting additional insights. Our findings show that cluster membership is not in general associated with a higher propensity to cooperate. Instead, we need to take a closer look at the clusters themselves in order to disentangle the effects of cluster membership on the timing and propensity to cooperate.

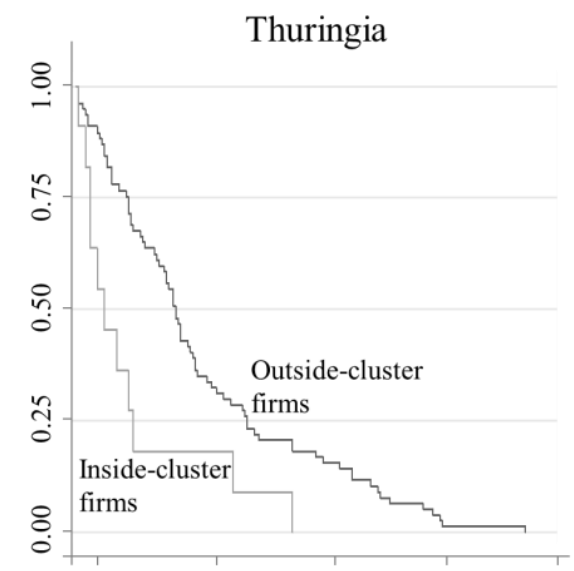

Analysis time (in century months)
Wilcoxon (Breslow) test, equality of survivor functions

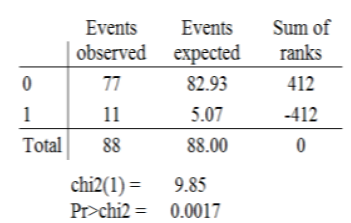

Tarone-Ware test, equality of survivor functions

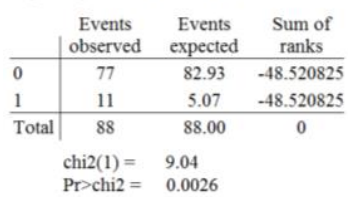

Bavaria

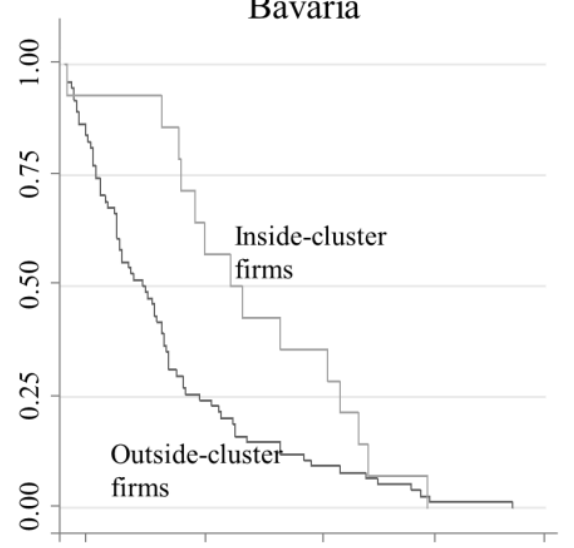

Analysis time (in century months)

Log-rank test,

equality of survivor functions Events Events

\begin{tabular}{|c|c|c|}
\hline & observed & expected \\
\hline 0 & 74 & 65.62 \\
\hline 1 & 14 & 22.38 \\
\hline \multirow[t]{2}{*}{ Total } & 88 & 88.00 \\
\hline & $\begin{array}{l}\operatorname{chi} 2(1)= \\
\operatorname{Pr}>\text { chi2 }=\end{array}$ & $\begin{array}{l}4.46 \\
0.0346\end{array}$ \\
\hline
\end{tabular}
$\mathrm{Pr}>$ chi2 $=0.0346$

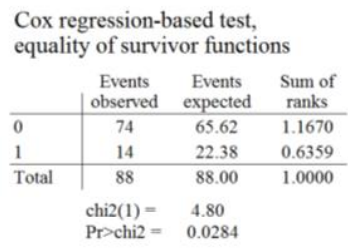

Wilcoxon (Breslow) test, equality of survivor functions

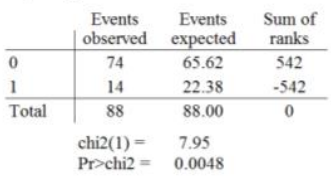

Tarone-Ware test, equality of survivor functions

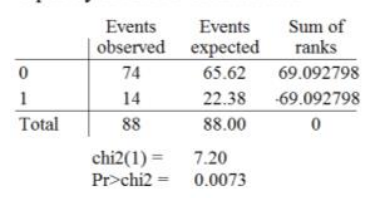




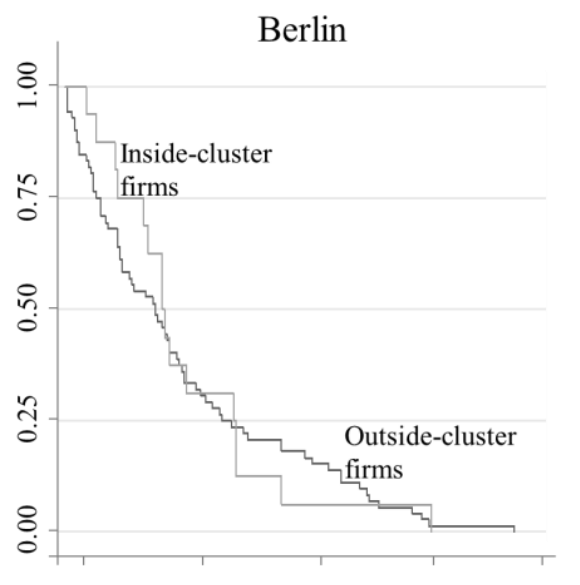

Analysis time (in century months)

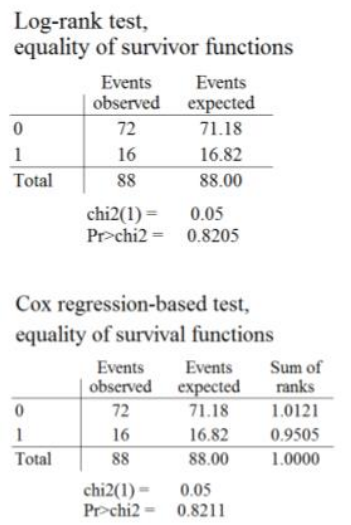

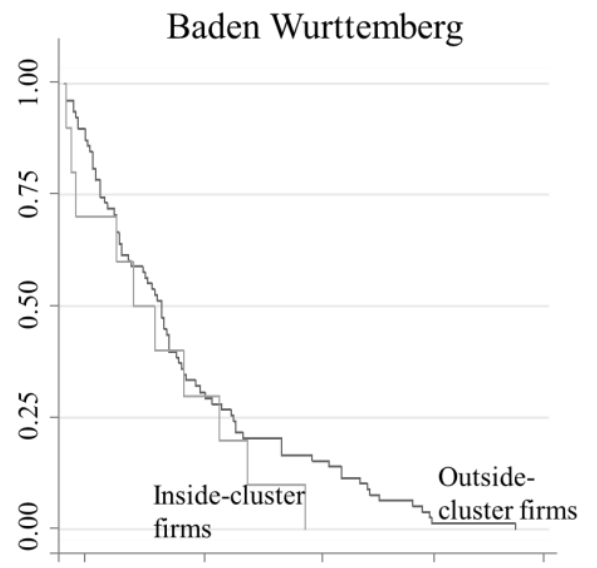

Analysis time (in century months)

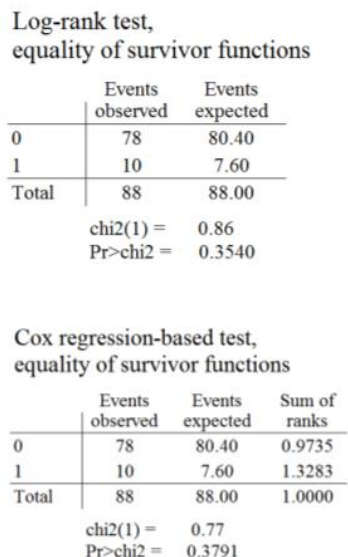

Wilcoxon (Breslow) test, equality of survivor functions

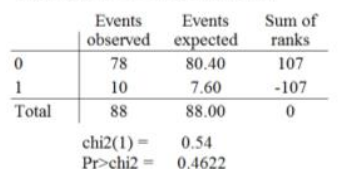

Tarone-Ware test, equality of survivor functions

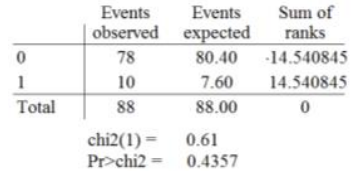

Fig. 4. Timing of cooperating and entering the network, by cluster membership. (Source: Own calculations)

\section{Discussion, Conclusion and Further Research}

This study is motivated by a desire to deepen our understanding of how and why firms enter an industry's innovation network. Thus we run an empirical investigation of the extent to which firm-specific, co-operation-specific and geographical determinants affect a firm's timing and propensity to co-operate the first time within the German laser industry innovation network.

We conduct a non-parametric event history analysis to provide empirical evidence of German LSMs' propensity to co-operate for the first time and enter the industry's innovation network. Our analysis is based on the full population of German and consider all nationally and supranationally funded $R \& D$ co-operation projects over a period of more than two decades. Nonetheless, as in any empirical study, this investigation has some limitations. In particular, owing to data constraints, not all co-operation drivers can be considered. However, the selection of firm-specific, co-operation-specific, and geographical determinants provides insights of some of the forces at work. 
Our study has interesting implications for both policy makers and practitioners. Firstly, our findings show that micro firms enter the network significantly later than small-sized and large firms but fail to explain the late entry of medium-sized firms. The underlying logic of this finding is straightforward. Even though SMEs are more dependent on access to external knowledge sources via interorganisational R\&D linkages in order to keep pace with larger competitors, there are several factors hampering their ability to initiate $R \& D$ linkages for the first time. This finding supports the view of many European countries and regions that realised innovation policy programs for SMEs in order to strengthen networks of R\&D and innovation (e.g., Muldur et al., 2006; OECD, 2008). In this way, the joint research potential of SMEs becomes effective more quickly. In further research it would be interesting to disentangle the extent to which factors such as search costs, a lack of alliance management capabilities or simply the absence of standardised cooperation interfaces explain the delayed entry of SMEs. Our second result is surprising. The findings show that the choice of cooperation type (national or international) has no significant impact on a firm's timing in entering the network. Differences between nationally oriented and internationally oriented R\&D co-operation projects seem to play only a subordinate role in the German laser industry. A potential explanation is that previously existing interpersonal networks between decision makers relativise culturally contingent co-operation barriers.

The findings of the final empirical analysis indicate that cluster membership can have quite different effects on a firm's timing in entering the network. Traditionally, it has been argued that a geographically crowded region provides several benefits for firms. It appears that firms in some regions (e.g., Thuringia) tend to cooperate earlier and to have a significantly higher propensity to co-operate than those in other regions (e.g., Bavaria). A plausible explanation for the comparably low cooperation propensity and late entries in Bavaria can be found in the spatial lock-in argument (cf. Boschma, 2005; Boschma and Frenken, 2010). In terms of policy making, this finding means that clustering processes are important but no remedy in themselves. Very specialised industries, like the laser industry, depend heavily on co-operation partners anywhere in Germany and beyond. This corresponds to the findings on national versus international networks mentioned above.

Despite these initial steps towards a deeper understanding of network change, we still face considerable challenges. From a conceptual perspective, there is still much to be done. The next logical step is to include consecutive as well as repeated co-operation events in the analysis. This, however, requires the explicit consideration of network path dependencies. In line with 
Glueckler (2007) we are convinced that the sequential analysis of co-operation strategies and co-operation options is crucial to understanding structural network change.

From an empirical point of view we are still at an early stage. The next steps on our research agenda are straightforward. Firstly, we will consider consecutive and repeated co-operation events. Secondly, we have to find a way to analyse empirically the structural consequences of micro-level network change processes. Finally, our database must be extended in several ways in order to establish a comprehensive empirical basis for the analysis of evolutionary network change processes. We are currently making progress in this direction by including nonfunded strategic alliances.

The methods used in this study provide a good starting point for an exploratory analysis of network change processes but they are limited in several ways. Both parametric and semiparametric estimation approaches provide a wide range of empirical models that can be used for an in-depth analysis of tie-formation and tie-termination processes at the firm level. In addition, other powerful methods are now available, such as agent-based simulation approaches. For instance, the socalled KENE approach (Gilbert et al., 2007; Pyka et al., 2007) allows a firm's knowledge base, learning processes and the transfer of knowledge in complex network structures to be modeled and simulated. Such agent-based models can be applied to simulate micro-level firm behaviour which shapes macro-level network patterns (Mueller et al., 2014).

\section{Acknowledgements}

We thank Guido Buenstorf, Matthias Geissler, Michael Fritsch and the other members of the LASSSIE project consortium for providing us with proprietary raw data and other valuable information on the dynamics of the German laser industry. Furthermore, we benefited from audience comments and suggestions at several conferences, most notably the XXIV ISPIM conference 2013, Helsinki, Finland. We assume responsibility for any errors. 


\section{References}

Ackerlof, GA (1970). The market for "lemons". Quality uncertainty and the market mechanism. Quarterly Journal of Economics, 84(3), 488-500.

Albert, R and AL Barabasi (2002). Statistical mechanics of complex networks. Reviews of Modern Physics, 74(1), 47-97.

Allison, PD (1984). Event History Analysis - Regression for Longitudinal Event Data. London: Sage Publications.

Amburgey, T, BS Aharonson and D Tzabbar (2009). Heterophily In Inter-Organizational Network Ties. Conference paper: 25th EGOS Colloquium. Barcelona.

Audretsch, DB and MP Feldman (1996). R\&D spillovers and the geography of innovation and production. American Economic Review, 86(3), 630-640.

Balland, PA, M De Vaan and R Boschma (2012). The dynamics of interfirm networks along the industry life cycle: The case of the global video game industry, 1987-2007, Journal of Economic Geography, 13(5), 1-25.

Barabasi, A-L and R Albert (1999). Emergence of scaling in random networks, Science, 286(15), 509-512.

Barkema, HG, JH Bell and JM Pennings (1996). Foreign entry, cultural barriers, and learning, Strategic Management Journal, 17(2), 151-166.

Barney, JB (1991). Firm resources and sustained competitive advantage, Journal of Management, 17(1), 99-120.

Barron, DN, E West and MT Hannan (1994). A time to grow and a time to die: Growth and mortality of Credit Unions in New York City, 1914-1990, American Journal of Sociology, 100(2), 381-421.

Baum, JA, T Calabrese and BS Silverman (2000). Don't go it alone: Alliance network composition and startups' performance in Canadian biotechnology. Strategic Management

Journal, 21(3), 267-294.

Blossfeld, HP and G Rohwer (2002). Techniques of Event History Analysis - New Approaches to Causal Analysis. London: Lawence Erlbaum Associates Publishing.

Blossfeld, HP, K Golsch and G Rohwer (2007). Event history analysis with Stata. London: Lawrence Erlbaum Associates, Publishers.

Boschma, R (2005). Proximity and innovation: A critical assessment, Regional Studies, 39(1), $61-74$. 
Boschma, R and K Frenken (2010). The spatial evolution of innovation networks: A proximity perspective. In The Handbook of Evolutionary Economic Geography, R Boschma and R Martin (eds.), pp. 120-135. Cheltenham: Edward Elgar Publishing.

Broeckel, T and H Graf (2011). Public research intensity and the structure of German R\&D networks: A comparison of ten technologies. Economics of Innovation and New

Technology, 1-28.

Buchmann, T and A Pyka (2015). The evolution of innovation networks: The case of a publicly funded German automotive network, Economics of Innovation and New Technology (Special Issue: Productivity, Networks and Knowledge Flows), 24(1-2), 114-139.

Buchmann, T, D Hain, M Kudic and M Mueller (2013). Exploring the co-evolutionary nature of innovation networks - new evidence from a stochastic actor-based simulation approach, Conf. Proc. 8th European Meeting on Applied Evolutionary Economics, 10th - 12th June, Cote d'Azur, France.

Buenstorf, G (2007). Evolution on the shoulders of giants: Entrepreneurship and firm survival in the German laser industry, Review of Industrial Organization, 30(3), 179-202.

Cantner, U and H Graf (2011). Innovation Networks: Formation, Performance and Dynamics. In Handbook on the Economic Complexity of Technological Change.

C Antonelli (ed.), pp. 366-394. Celtenham UK: Edward Elgar Publishing. Carlsson, B, S Jacobsson, M Holmen and A Rickne (2002). Innovation systems: Analytical and methodological issues, Research Policy, 31(2), 233-245.

Cassi, L, N Corrocher, F Malerba and N Vonortas (2008). Research networks as infrastructure for knowledge diffusion in European regions. Economics of Innovation and New Technology, 17(7), 665-678.

Chesbrough, H (2003). Open Innovation - The New Imperative for Creating and Profiting from Technology. Boston: Harvard Business School Press.

Cleves, MA, WW Gould, RG Gutierrez and YU Marchenko (2008). An Introduction to Survival Analysis Using Stata, 2nd Ed. College Station: Stata Press.

Coff, RW (2003). The emergent knowledge-based theory of competetive advantage: An evolutionary approach to integrating economics and management. Managerial and Decision Economics, 24(4), 245-251.

Dacin, TM, MA Hitt and E Levitas (1997). Selecting partners for successful international alliances: Examination of U.S. and Korean firms. Journal of World Business, 32(1), 3-16.

Dierickx, I and K Cool (1989). Asset stock accumulation and sustainability of competitive advantage. Management Science, 35(12), 1504-1511. 
European Commission (2005). The New SME Definition - User Guide and Model Declaration. Brussels: Enterprise and Industry Publications.

Feldman, MP (1999). The new economics of innovation, spillovers and agglomeration: A review of empirical studies. Economics of Innovation and New Technology, 8(1), 5-25.

Fornahl, D, T Broeckel and R Boschma (2011). What drives patent performance of German biotech firms? The impact of R\&D subsidies, knowledge networks and their location. Papers in Regional Science, 90(2), 395-418.

Fritsch, M and LF Medrano (2015). New Technology in the Region-Agglomeration and Absorptive Capacity Effects on Laser Technology Research in West Germany, (1960-2009), Economics of Innovation and New Technology (Special Issue: Productivity, Networks and Knowledge Flows), 24(1-2), 65-94.

Fritsch, M and V Slavtchev (2007). Universities and innovation in space. Industry and Innovation, 14(2), 202-218.

Giesekus, J (2007). The Industry for beam sources and optical components - A market overview by SPEKTARIS (english translation), Laser Technik Journal, 4(5), 11-13.

Gilbert, N, P Ahrweiler and A Pyka (2007). Learning in innovation networks: Some simulation experiments. Physica A: Statistical Mechanics and its Applications, 378(1), 100-109.

Giuliani, E (2010). Network dynamics in regional clusters: The perspective of an emerging economy, Papers in Evolutionary Economic Geography (PEEG), 10(14), [online].

Glueckler, J (2007). Economic geography and the evolution of networks. Journal of Economic Geography, 7(5), 619-634.

Goerzen, A (2005). Managing alliance networks: Emerging practices of multinational corporations. Academy of Management Executive, 19(2), 94-107.

Gould, GR (1959). The laser: Light amplification by stimulated emission of radiation. Ann Arbor Conference on Optical Pumping, Conference Proceedings, June 15-18, pp. 128-130.

Grant, RM and C Baden-Fuller (2004). A knowledge accessing theory of strategic alliances. Journal of Management Studies, 41(1), 61-84.

Grupp, H (2000). Learning in a science driven market: The case of lasers. Industrial and Corporate Change, 9(1), 143-172.

Guimera, R, B Uzzi, J Spiro and LA Armaral (2005). Team assembly mechanisms determine collaboration network structure and team performance. Science, 308(29), 697-702.

Gulati, R (2007). Managing Network Resources-Alliances, Affiliations and Other Relational Assets. New York: Oxford University Press. 
Gulati, R and M Gargiulo (1999). Where do interorganisational networks come from? American Journal of Sociology, 104(5), 1439-1493.

Gunasekaran, A (1997). Essentials of international and joint R\&D projects. Technovation, 17(11-12), 637-647.

Hagedoorn, J (1993). Understanding the rational of strategic technology partnering organisational modes of co-operation and sectoral differences. Strategic Management Journal, 14(5), 371-385.

Hagedoorn, J (2002). Inter-firm R\&D partnership: An overview of major trends and patterns since 1960. Research Policy, 31(4), 477-492.

Hagedoorn, J (2006). Understanding the cross-level embeddedness of interfirm partnership formation. Academy of Management Review, 31(3), 670-680.

Hagedoorn, J, AN Link and NS Vonortas (2000). Research partnerships. Research Policy, 29(4-5), 567-586.

Hamel, G (1991). Competition for competence and inter-partner learning within international strategic alliances. Strategic Management Journal, 12(1), 83-103.

Hecht, J (2010). The first half-century of laser development - how a solution that once was looking for a problem has become part of everyday life. Laser Technik Journal, 7(4), 20-25.

Hofstede, G (2001). Culture's Consequences: Comparing Values, Behaviors, Institutions, and Organisations Across Nations, 2nd Ed. Thousand Oaks, California: Sage Publications.

Hite, JM and WS Hesterly (2001). The evolution of firm networks: From emergence to early growth of the firm. Strategic Management Journal, 22(3), 275-286.

Jenssen, JI and E Nybakk (2009). Interorganisational innovation promoters in small knowledgeintensive firms. International Journal of Innovation Management, 13(3), 441-465.

Jenssen, JI and E Nybakk (2013). Inter-organisational networks and innovation in small, knowledge-intensive firms: A literature review. International Journal of Innovation Management, 17(2), 27-54.

Kale, P, H Singh and H Perlmutter (2000). Learning and protection of proprietary assets in strategic alliances: Building relational capital. Strategic Management Journal, 21(3), 217237.

Kaplan, EL and P Meier (1958). Nonparametric estimation from incomplete observations. Journal of the American Statistical Association, 53, 457-481.

Kirman, A (1993). Ants, rationality, and recruitment. The Quarterly Journal of Economics, 108(1), 137-156. 
Koka, BR, R Madhavan and JE Prescott (2006). The evolution of interfirm networks: Environmental effects on patterns of network change. Academy of Management Review, $31(3), 721-737$.

Kudic, M (2015). Innovation networks in the German laser industry - Evolutionary Change, Strategic Positioning and Firm Innovativness. (Heidelberg, Springer).

Kudic, M, K Guhr, I Bullmer and J Guenther (2011). Cooperation intensity and cooperation funding in the German laser industry (english translation), Wirtschaft im Wandel, 17(3), $121-129$.

Lavie, D and SR Miller (2008). Alliance portfolio internationalisation and firm performance. Organization Science, 19(4), 623-646.

Lu, JW and PW Beamish (2006). Partnering strategies and performance of SMEs' international joint ventures. Journal of Business Venturing, 21(4), 461-486.

Lundvall, B-A (1992). National Systems of Innovation - Towards a Theory of Innovation and Interactive Learning. London: Pinter.

Maiman, TH (1960). Stimulated optical radiation in ruby. Nature, 187(4736), 493-494.

Malerba, F (2002). Sectoral systems of innovation and production. Research Policy, 31, 247264.

Mayer, A (2004). Laser in der material processing - A market overview (english translation), Laser Technik Journal, 1(1), 9-12.

McPherson, M, L Smith-Lovin and JM Cook (2001). Birds of a feather: Homophily in social networks. Annual Review of Sociology, 27(1), 415-444.

Moeller, K and S Svahn (2006). Role of knowledge in value creation in business nets. Journal of Management Studies, 43(5), 985-1007.

Moeller, K and S Svahn (2009). How to influence the birth of new business fields - Network perspective. Industrial Marketing Management, 38(4), 450-458.

Mowery, DC, JE Oxley and BS Silverman (1996). Strategic alliances and interfirm knowledge transfer. Strategic Management Journal, 17(2), 77-92.

Mueller, M, T Buchmann and M Kudic (2014). Micro strategies and macro patterns in the evolution of innovation networks. In Simulating Knowledge Dynamics in Innovation Networks, N Gilbert, P Arweiler and A Pyka (eds.), New York, NY: Springer, Berlin, Heidelberg, New York, pp. 73-95.

Muldur, U, F Corvers, H Delanghe, J Dratwa, D Heimberge, B Sloan and S Vanslembrouck (2006) A New Deal for an Effective European Research Policy: The Design and Impacts of the 7th Framework Programme. Netherlands: Springer. 
Nakamura, M, I Vertinsky and C Zietsam (1997). Does culture matter in inter-firm cooperation? Research consortia in Japan and the USA. Managerial and Decision Economics, 18, 153175.

OECD (2008). OECD Science, Technology and Industry Outlook. OECD: Paris.

Peteraf, MA (1993). The cornerstones of competitive advantage: A resource-based view. Strategic Management Journal, 14(3), 179-191.

Powel, WW, KW Koput and L Smith-Doerr (1996). Interorganisational collaboration and the locus of innovation - networks of learning in biotechnology. Administrative Science Quarterly, 41(1), 116-145.

Powell, WW, DR White, KW Koput and J Owen-Smith (2005). Network dynamics and field evolution: The growth of interorganisational collaboration in the life sciences. American Journal of Sociology, 110(4), 1132-1205.

Pyka, A (2002). Innovation networks in economics: From the incentive-based to the knowledge based aproaches. European Journal for Innovation Management, 5(3), 152-163.

Pyka, A (2007). Innovation networks. In Elgar Companion to Neo-Schumpeterian Economics, H Hanusch and A Pyka (eds.), pp. 360-377. Cheltenham: Edward Elgar Publishing.

Pyka, A, N Gilbert and P Ahrweiler (2007). Simulating knowledge-generation and distribution processes in innovation collaborations and networks. Cybernetics and Systems: An International Journal, 38(7), 667-693.

Rothaermel, FT (2001). Incumbent's advantage through exploiting complementary assets via interfirm cooperation. Strategic Management Journal, 22(6), 687-699.

Roxenhall, T (2013). Network structure and innovation in strategic innovation networks. International Journal of Innovation Management, 17(2), 1-20.

Scherngell, T and MJ Barber (2009). Spatial interaction modelling of cross-region R\&D collaborations: Empirical evidence from the 5th EU framework programme. Papers in Regional Science, 88(3), 531-546.

Scherngell, T and MJ Barber (2011). Distinct spatial characteristics of industrial and public research collaborations: Evidence from the fifth EU framework programme. Annals of Regional Science, 46(2), 247-266.

Schilke, O and A Goerzen (2010). Alliance management capability: An investigation of the construct and its measurement. Journal of Management, 36(5), 1192-1219.

Schwartz, M, F Peglow, M Fritsch and J Guenther (2012). What Drives Innovation Output from Subsidised R\&D Cooperation Projects? - Project-Level Evidence from Germany. Technovation, 36(6), 358-369. 
Sivadas, E and RF Dwyer (2000). An examination of organisational factors influencing new product success in internal and alliance-based processes. Journal of Marketing, 64(1), 3149.

Snijders, TA, GG Van De Bunt and CE Steglich (2010). Introduction to actor-based models for network dynamics. Social Networks, 32(1), 44-60.

Spence, M (1976). Informational aspects of market structure: An introduction. Quarterly Journal of Economics, 90(4), 591-597.

Tidd, J, J Bessant and K Pavitt (2005). Managing Innovation. Chichester: Wiley.

Van de Bunt, GG and P Groenewegen (2007). An actor-oriented dynamic network approach. Organizational Research Methods, 10(3), 463-482.

Wasserman, S and K Faust (1994). Social Network Analysis: Methods and Applications. Cambridge University Press: Cambridge.

Wernerfelt, B (1984). A resource based view of the firm. Strategic Management Journal, 5(2), 171-180. 